\title{
Treatment-seeking behaviour for febrile illnesses and its implications for malaria control and elimination in Savannakhet Province, Lao PDR (Laos): a mixed method study
}

Bipin Adhikari ${ }^{1,2,3^{*}}$ D , Koukeo Phommasone ${ }^{4}$, Tiengkham Pongvongsa ${ }^{5}$, Palingnaphone Koummarasy ${ }^{4}$, Xayaphone Soundala ${ }^{4}$, Gisela Henriques ${ }^{1,6}$, Pasathorn Sirithiranont ${ }^{1}$, Daniel M. Parker ${ }^{7}$, Lorenz von Seidlein ${ }^{1,2}$, Nicholas J. White ${ }^{1,2}$, Nicholas P. J. Day ${ }^{1,2}$, Arjen M. Dondorp ${ }^{1,2}$, Paul N. Newton 2,4, Phaik Yeong Cheah ${ }^{1,2,8}$, Christopher Pell ${ }^{9,10}$ and Mayfong Mayxay ${ }^{2,4,11}$

\begin{abstract}
Background: How people respond to febrile illness is critical to malaria prevention, control, and ultimately elimination. This article explores factors affecting treatment-seeking behaviour for febrile illnesses in a remote area of Lao PDR.

Methods: Household heads or their representatives $(n=281)$ were interviewed using a structured questionnaire. A total of twelve focus group discussions (FGDs) each with eight to ten participants were conducted in four villages. In addition, observations were recorded as field notes $(n=130)$ and were used to collect information on the local context, including the treatment seeking behaviour and the health services.

Results: Almost three-quarters (201/281) of respondents reported fever in past two months. Most (92\%, 185/201) sought treatment of which $80 \%(149 / 185)$ sought treatment at a health centre. Geographic proximity to a health centre $(A O R=6.5 ; C l=1.74-24.25$; for those $<3.5 \mathrm{~km}$ versus those $>3.6 \mathrm{~km}$ ) and previous experience of attending a health centre $(A O R=4.7 ; C l=1.2-19.1)$ were strong predictors of visiting a health centre for febrile symptoms. During FGDs, respondents described seeking treatment from traditional healers and at health centre for mild to moderate illnesses. Respondents also explained how if symptoms, including fever, were severe or persisted after receiving treatment elsewhere, they sought assistance at health centres. Access to local health centres/hospitals was often constrained by a lack of transportation and an ability to meet the direct and indirect costs of a visit.

Conclusion: In Nong District, a rural area bordering Vietnam, people seek care from health centres offering allopathic medicine and from spiritual healers. Decisions about where and when to attend health care depended on their economic status, mobility (distance to the health centre, road conditions, availability of transport), symptoms severity and illness recognition. Current and future malaria control/elimination programmes could benefit from greater collaboration with the locally accessible sources of treatments, such as health volunteers and traditional healers.
\end{abstract}

Keywords: Health seeking, Malaria, Febrile illness, On the counter, Resistance, Elimination

\footnotetext{
* Correspondence: biopion@gmail.com

${ }^{1}$ Mahidol-Oxford Tropical Medicine Research Unit, Faculty of Tropical

Medicine, Mahidol University, Bangkok, Thailand

${ }^{2}$ Centre for Tropical Medicine and Global Health, Nuffield Department of

Medicine, University of Oxford, Oxford, UK

Full list of author information is available at the end of the article
}

(c) The Author(s). 2019 Open Access This article is distributed under the terms of the Creative Commons Attribution 4.0 International License (http://creativecommons.org/licenses/by/4.0/), which permits unrestricted use, distribution, and reproduction in any medium, provided you give appropriate credit to the original author(s) and the source, provide a link to the Creative Commons license, and indicate if changes were made. The Creative Commons Public Domain Dedication waiver (http://creativecommons.org/publicdomain/zero/1.0/) applies to the data made available in this article, unless otherwise stated. 


\section{Background}

Over recent years, the decline in malaria incidence and malaria-related mortality in the Greater Mekong Sub-region (GMS) has prompted countries in the region to consider the prospect of malaria elimination [1]. As states in the GMS adopt strategies to eliminate malaria, identifying and appropriately managing the remaining cases becomes increasingly critical. In the GMS, the remaining malaria cases together with the burden of parasite reservoir are clustered in hard-to-reach populations, with high mosquito densities, abundance of larval habitats, and human-mosquito interactions, which results from time spent working in forests and the practice of swidden cultivation [2-7].

Laos has made a substantial progress in malaria control and elimination [3]. Nevertheless, country's southern provinces are still malaria endemic, recording high transmission, with a 2014 annual parasite index (API) of 20.3, in contrast to 7.3 nationally [8]. Five southern provinces (Savannakhet, Saravan, Sekong, Attapeu and Champasak) accounted for $96 \%$ of the total malaria cases in 2014 and $36 \%$ of the total national population of seven million $[3,8]$. As part of the national strategic plan for malaria control and elimination, Laos aims to eliminate $P$. falciparum by $2030[3,9,10]$.

Strategies piloted for malaria elimination in Laos (and the wider GMS) include the distribution of long lasting insecticide treated bed nets (LLINs), mass drug administrations (MDAs) and strengthening of village malaria/health worker (VMW) networks to ensure appropriate malaria diagnosis and case management [8,10-13]. Several factors influence the success of these interventions: accessibility particularly in the rainy season; inadequate healthcare infrastructure; poverty; and human behaviour [14-17].

How people respond to febrile illness is critical to malaria prevention, control, and ultimately elimination [18-22]. The many factors that influence behaviour include people's understanding of illness, their past experiences, and the available methods of diagnosis and treatment [15, 23]. Understanding treatment seeking behaviour and its underpinnings is important for the design of an intervention package and, particularly, the design of the accompanying health messages and the health education tools [21, 24, 25].

In Lao PDR, several studies have explored health seeking behaviour for a number of health conditions, such as maternal and child health [26, 27], sexually transmitted infections [28], respiratory infections [29] and the impacts of available health care infrastructure [30-34]. There is a paucity of published research on health seeking behaviour for febrile illnesses in Laos, specifically focusing on population living in remote, malaria endemic regions. Drawing on qualitative and quantitative data collected prior to a pilot study evaluating targeted malaria elimination (TME), this article examines treatment seeking behaviour for febrile illnesses. The main objective is to explore the patterns and determinants of treatment seeking behaviour for febrile illnesses in four malaria endemic villages of Nong District in Savannakhet province.

\section{Methods}

This mixed-methods study combined a questionnaire-based survey with focused group discussions (FGDs) and structured observations, which were recorded as field notes. The study employed a cross-sectional study design. The combination of methods allowed for triangulation of formal data collection techniques (questionnaire and FGDs) with recording information on informal behaviours and utterance in real-life situations. The findings from the questionnairebased survey were explored using three qualitative data collection techniques. This provided further information underlying the responses provided in the survey.

The questionnaire-based survey enabled the research team to collect community-wide data and elicit the opinions of all the households in the targeted communities. Such a community-wide approach was taken in the context of MDA, which targeted all community members regardless of malaria infection status. In the villages selected for this intervention (which also included blood tests over three consecutive months), it was critical to explore thoroughly the treatment seeking behaviour for the febrile illnesses and malaria so as to design a tailored community engagement to maximize the uptake of MDA [21, 24]. FGDs were conducted about a week after the completion of the questionnaire survey to explore the reasons that underpinned responses to the questionnaire survey. Observational field notes were collected throughout the study period. Observations of behaviours and utterances in the communities where MDA was conducted were used to provide wider information on the local social and cultural context relevant to malaria, febrile illnesses, preventive measures, treatment seeking and the wider healthcare situation, which are not dictated by the themes and topics of the questionnaire survey and FGDs. The observations were recorded in field notes and typed up for analysis.

The design of the questionnaire was based on a review of literature discussed below. The themes addressed in the FGD guide were designed to reflect the topics covered in the questionnaire.

\section{Study context}

The questionnaire-based survey and FGDs were conducted between November and December 2015, prior to the start of the TME pilot study [3]. Based on existing malaria endemicity data, two districts in Savannakhet (Nong and Thapangthong) were surveyed using ultrasensitive quantitative PCR (uPCR) and four villages in Nong District were ultimately selected for TME based on the high prevalence of asymptomatic malaria (Fig. 1) 


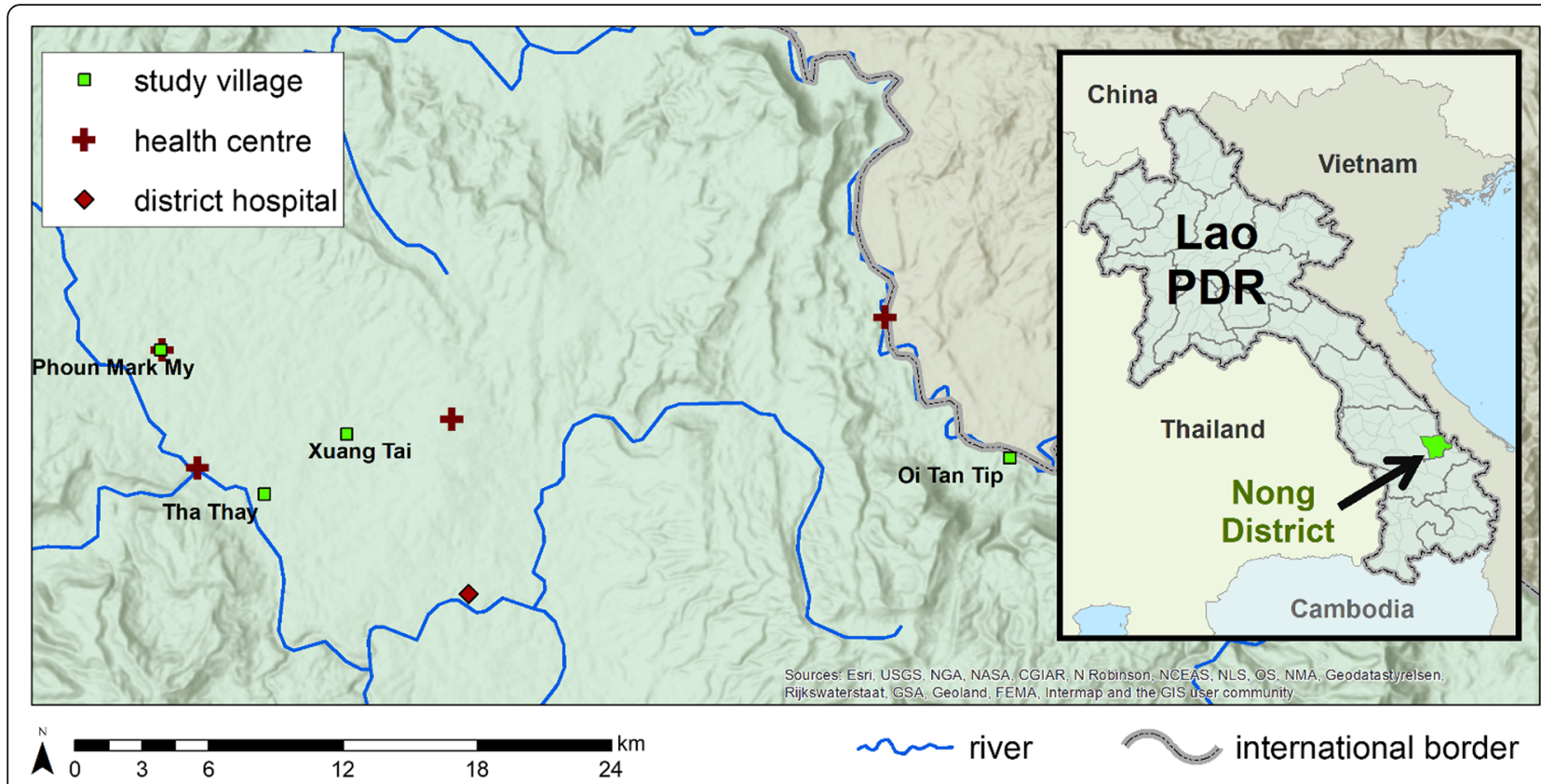

Fig. 1 Study villages, health centres and a hospital in Nong district, Savannakhet province, Lao PDR. The map in Fig. 1 was created for this manuscript by one of the co-authors (DMP) using ArcMap 10.5.1 and GPS coordinates taken from the field locations

[3]. The current study was a sub-study of the main TME pilot and data were collected in the TME villages.

\section{Study participants and questionnaire}

Villages comprised population sizes between 300 and 500 residents: Oi Tantip $(\mathrm{OTP}=512)$, Phoun Mak Mee (PMM $=480)$, Thate $(\mathrm{TT}=526)$ and Xuang Tai $(\mathrm{XT}=371)$ [20]. The study population consisted of one member, preferably the household head, of every household in the four TME villages. There were total of 281 households in 4 villages $(\mathrm{OTP}=65, \mathrm{PMM}=74, \mathrm{TT}=82$ and $\mathrm{XT}=60)$. Each respondent, representing a household, was interviewed using a structured questionnaire that consisted of questions on socio-demographic characteristics and health seeking behaviour in response to febrile illness.

Two Laotian social scientists interviewed respondents at their household after obtaining written informed consent, mostly in the Lao language. For a few respondents who could not speak the Lao language, a bilingual local study coordinator translated on site to note down the responses by interviewers. A household head or any other representative of house above 18 years old were selected for the study. If representatives of the household were not present during the survey, they were followed up during the consecutive days. None of the household representatives refused to participate. Respondents representing a total of two households were away and interviewed once they returned. Representatives from all households within four selected villages were ultimately interviewed. Interviews lasted between 30 and $45 \mathrm{~min}$.
The questionnaire was drafted in English with the help of two Laotian social scientists, translated into Lao Language and back translated to English to ensure accuracy and validity. For this study, the questionnaire consisted of three parts: I general information about the interview, interviewer and interviewee; II socio-demographic characteristics, such as age, sex, religion and marital status; and III health seeking behaviour [9]. Socio-economic variables were designed after reviewing the past studies from various regions within Laos [28, 29, 34], Vietnam [35], Cambodia [36], Thai-Myanmar border [37] and The Gambia [37, 38]. In addition, questions on socio-economic status have been recently used in sub-studies from the TME villages in Laos $[9,12]$. Questions on health seeking behaviour for febrile illness were constructed after reviewing the past studies, conducted in Laos [28, 29], Cambodia [36], Uganda [39] and Ghana [40] and further adapted to suit the local cultural context.

All data are drawn from participants' responses apart from the approximate distance between household and the health centre, which were estimated by the interviewers. Based on the pre-testing of the questionnaire amongst the experts, respondents around Mahosot Hospital and the households around Nong district, history of fever in last two months were (chosen) asked to minimize recall bias. The question on health seeking behaviour was: "if you have fever, where do you usually go for treatment first?" Responses that mentioned allopathic health care services, such as health centre/health post, private pharmacies, mobile drug vendors, village health 
volunteers, district, provincial and central hospitals were categorized as "Allopathic health services" and other services such as traditional healers, including spiritual healers and sorcerers were categorized as "non-allopathic health services".

Two social scientists pre-tested the data collection tools, as administering it first to the site PI and two authors and later to 15 volunteer participants around Mahosot Hospital in Vientiane. Further pre-testing was carried out in Nong District with six households. Ambiguities were corrected and simplified.

\section{Focus group discussions and field notes}

Twelve FGDs were conducted with a total of 100 participants (with 8-10 participants per each FGD) from four villages and their sub-villages (Table 1). There were a total of six villages/sub-villages. Two focus group discussions (one each for males and females) were conducted in each of these six villages/sub-villages. In each village/ sub-village, a village head was asked to invite eight to 10 community members to participate in a FGD. However, the number of participants attended was always higher than that required. Considering the sensitivity around turning them away in light of their enthusiasm, a random sample of eight to 10 adult participants (above 18 years and consenting to participate) were selected using a lottery method during village meetings. Male and female participants were interviewed in separate groups by a male and a female interviewer respectively. Aware of the local social and cultural context, whereby patriarchy is strong and there is a tendency for conformism among females when mixed with males groups, male and female FGDs were conducted separately $[12,41]$.
The discussions took place in the home of one of the villagers. The interviewers made use of an open-ended questionnaire guide (FGD guide) developed by the study team which included sections I and II. The section I explored the "treatment seeking behaviour for febrile illnesses and malaria", and section II explored "knowledge and attitude related to malaria, preventive measures and mass drug administration" [9]. For the purpose of this study, section I was utilized to focus on health seeking behaviour on broad themes such as "When and how do you decide to go for treatment when you are sick?" Each FGD lasted for about 60 to $120 \mathrm{~min}$. The discussions were conducted in Pasha Lao and translated into the local Lao Theung language on site. In this article, "Lao Theung" refers to language spoken by members of people who reside in these villages. All respondents gave written consent to record and analyse their replies. The discussions were recorded, transcribed and translated into English by the social scientists who conducted the FGDs.

In addition to FGDs, field notes were collected based on the observation of the TME- related activities, including the local health infrastructure, road conditions, transportation means and common health practices. Field notes contained the location, subject of the notes, date and descriptions of the issues in question (for example: health services, traditional practices) based on the formal/informal discussions, meetings and interviews. Field notes were taken by BA, XS and PK in English with on-site translation where necessary. Field notes were collected each time study team made a visit to the study villages and each field note represented a day's observation. A total of 130 field notes were collected from September 2015 to August 2016. Observations were made at every visit to the villages and these were recorded as field notes.

Table 1 Socio-demographic characteristics of FGD Participants $(n=100)$

\begin{tabular}{|c|c|c|c|c|c|c|c|}
\hline \multirow[b]{2}{*}{ Characteristics } & \multirow{2}{*}{$\begin{array}{l}\text { Total } \\
\text { Number (\%) }\end{array}$} & \multicolumn{6}{|c|}{ Village: Number (\%) } \\
\hline & & $\mathrm{Oi}$ & Tantip & PMM & Keng and Appok & $\Pi$ main & $\mathrm{XT}$ \\
\hline \multicolumn{8}{|l|}{ Age Group } \\
\hline$\leq 35$ years & $51(51)$ & $7(13.7)$ & $12(23.5)$ & $6(11.8)$ & $13(25.5)$ & $7(13.7)$ & $6(11.8)$ \\
\hline$>36$ years & $49(49)$ & $9(18.4)$ & $4(8.2)$ & $12(24.5)$ & $5(10.2)$ & $9(18.4)$ & $10(20.4)$ \\
\hline \multicolumn{8}{|c|}{ Mean $=37.58 \pm 12.71 ;$ Range $=18-80$ years } \\
\hline \multicolumn{8}{|l|}{ Sex } \\
\hline Male & $52(52)$ & $8(15.4)$ & $8(15.4)$ & $10(19.2)$ & $10(19.2)$ & $8(15.4)$ & $8(15.4)$ \\
\hline Female & $48(48)$ & $8(16.7)$ & $8(16.7)$ & $8(16.7)$ & $8(16.7)$ & $8(16.7)$ & $8(16.7)$ \\
\hline \multicolumn{8}{|l|}{ Occupation } \\
\hline Farmer & $100(100)$ & $16(16)$ & $16(16)$ & $18(18)$ & $18(18)$ & $18(18)$ & $16(16)$ \\
\hline \multicolumn{8}{|l|}{ Education Groups } \\
\hline Not attended school & $82(82)$ & $12(14.6)$ & $10(12.2)$ & $13(15.9)$ & $17(20.7)$ & $14(17.1)$ & $16(19.5)$ \\
\hline $1-5$ years & $16(16)$ & $4(25)$ & $5(31.3)$ & $5(31.3)$ & $1(6.3)$ & $1(6.3)$ & $0(0)$ \\
\hline$>6$ years & $2(2)$ & 0 & $1(50)$ & 0 & 0 & $1(50)$ & 0 \\
\hline
\end{tabular}




\section{Data management and analysis}

The questionnaire responses were entered into the Open Data Kit application on a smartphone in English (ODK; Available online: https://opendatakit.org/). Two social scientists conducted the interviews using two smartphones with on-site translation from either a local study coordinator or a bilingual village volunteer (fluent in Pasha Lao and Pasha Lao Theung) and were recorded in English in ODK. All collected data were extracted into Excel sheet (Microsoft Excel 2013) at Mahidol-Oxford Tropical Medicine Research Unit where data manager made cross-checks for any aberrant and outlying data. Data were analyzed in IBM SPSS Statistics for Windows, Version 24.0, Armonk, NY: IBM Corp.

Descriptive analysis, such as frequencies, percentages, were calculated and cross tabulated with health seeking behavior for febrile illness categorized into attending: 1 . Allopathic health services and 2. non-allopathic health services, using Chi squared and fisher exact test wherever appropriate. An association was considered significant at $p$ value $\leq 0.05$. Similarly, bivariate and multivariate analysis were conducted using logistic regression models to calculate odds ratio.

Based on the statistical significance ( $p$ value $\leq 0.05$ ) and relevance to the research question, variables were dichotomized as the presence of certain characteristics as 1 and their absence as 0 . These variables were analyzed using a multi-variate logistic regression model. At first, bivariate analysis was conducted with the dependent variable (health seeking behaviour categorized as attending allopathic health services as " 1 " and non-allopathic health services as "0") to calculate crude odds ratio. In the multi-variate model, age and sex were controlled for in the model to calculate the adjusted odds ratio.

Translated and transcribed FGD transcripts together with field notes were analysed using the qualitative data analysis software QSR NVivo 11. All transcripts were coded line-by-line using pre-set themes (deductive approach) as nodes. Further nodes were added for emerging themes (inductive approach). Data were coded by two researchers (BA and $\mathrm{CP}$ ) independently based on the pre-set themes which used to guide the overall study. Final codes for the study were decided based on the consensus amongst the researchers and relevance to the objective of this study. All the nodes were analysed for the pattern and the content to answer the research question. The quotes presented in this study are the typically expressed concerns and are not "occasional" or "exceptional".

\section{Results}

\section{Socio-demographic and household characteristics of participants}

A total of 100 participants from villages and sub-villages were included in 12 FGDs which had a similar proportion of male (52\%) and female (48\%) participants. Their mean age was 37 years, $82 \%$ did not attend school and all were farmers (Table 1).

Almost all respondents $(96 \%, 269 / 281)$ were from minority ethnic groups that consisted of Mangkong $=200$ $(71.2 \%)$, Tree $=64(22.8 \%)$, Phu Thai $=6(2.1 \%), \mathrm{Ta} O i=3$ (1.1\%), and Ka Tarng = $1(0.4 \%)$ and rest of the other included Vietnamese $=4(1.4 \%)$, and Lao Loum $=3(1.1 \%)$. The majority $(76 \% ; 201 / 281)$ were male, illiterate $76 \%$ $(214 / 281)$ and $73 \%(204 / 281)$ never attended formal education. Respondents who had attended a school and were of a high socio-economic status (25/27; $93 \%$ from monthly income of 240 USD attended health centre) compared to respondents from low (<60 USD; only 68\%; 131/192 attended health centre) socio-economic status $(p=0.007)$ were more likely to attend allopathic health services than respondents who had not attended school and were from a lower socio-economic status $(p=0.034$; Table 2$)$.

Respondents who reported attending allopathic health services, were more likely to own a tractor $(p=0.013)$ and lived further from the forest than respondents who owned no tractors or lived closer to the forest $(\mathrm{p}=0.007$; Table 3). Most households $(275 / 281 ; 98 \%)$ owned agricultural land and more than half $(153 / 281 ; 54 \%)$ owned a motorbike (Table 4).

\section{Health care infrastructure in study villages}

Based on the observations captured in field notes, all four villages; Oi Tan Tip (OTP), Phoun mak mee (PMM), Tha Thay (TT) and Xuang Tai (XT) were home to members of the Lao Theung ethnic minorities (Fig. 1). In this article, "Lao Theung" refers to residents of the study villages, a group composed of various ethnic groups, mostly Tree and Mangkong and are described below. OTP consisted two sub-villages Oi and Tantip both located at the border of Vietnam separated by the river. There is no health centre in OTP and primary health care was provided by village health volunteers. The nearest health centre was $10 \mathrm{~km}$ away. In PMM there is a health centre within the confines of the village and the houses were clustered into a single village. Three sub-villages (Appok, TT main and TT Geng) comprised TT and the nearest health centre was about $3 \mathrm{~km}$ away. In XT, there were two sub-villages (Xung Ngai and Xuang Gang) and the nearest health centre was about $5 \mathrm{~km}$ away. Amongst the villages, OTP was farthest from the district hospital (approximate distance to district hospital for OTP $\geq 40 \mathrm{~km}, P M M \geq 25 \mathrm{~km}$, $\mathrm{XT} \geq 10 \mathrm{~km}$ and TT was $\geq 18 \mathrm{~km}$ ). In all these government health facilities, diagnosis for malaria and treatment are available for free. Apart from the facilities offering primarily allopathic services, traditional healing embedded in spiritual practices, referred in this study as "Animist religion" was available to residents. 
Table 2 Treatment seeking behaviour for febrile illnesses in relation to socio-economic characteristics of the participants $(n=281)$

\begin{tabular}{|c|c|c|c|c|}
\hline \multirow[t]{2}{*}{ Characteristics } & Total $(n=281)$ & Allopathic health services $(n=200)$ & Non-allopathic health services $(n=81)$ & \multirow[t]{2}{*}{$p$-value } \\
\hline & Number (\%) & Number (\%) & Number (\%) & \\
\hline \multicolumn{5}{|l|}{ Villages } \\
\hline OTP & $65(23.1)$ & $52(26)$ & $13(16)$ & \multirow[t]{4}{*}{0.306} \\
\hline PMM & $74(26.3)$ & $50(25)$ & $24(29.6)$ & \\
\hline$\pi$ & $82(29.2)$ & $55(27.5)$ & $27(33.3)$ & \\
\hline$X T$ & $60(21.4)$ & $43(21.5)$ & $17(21)$ & \\
\hline \multicolumn{5}{|l|}{ Respondent status } \\
\hline Family head & $188(66.9)$ & $139(69.5)$ & $49(60.5)$ & \multirow[t]{3}{*}{0.309} \\
\hline Wife of family head & $70(24.9)$ & $45(64.3)$ & $25(30.9)$ & \\
\hline Other & $23(8.2)$ & $16(8)$ & $7(8.6)$ & \\
\hline \multicolumn{5}{|l|}{ Age Group } \\
\hline$\leq 30$ years & $91(32.4)$ & $63(31.5)$ & $28(34.6)$ & \multirow[t]{3}{*}{0.869} \\
\hline $31-50$ years & $138(49.1)$ & $99(49.5)$ & $39(48.1)$ & \\
\hline$\geq 51$ years & $52(18.5)$ & $38(19)$ & $14(17.3)$ & \\
\hline \multicolumn{5}{|l|}{ Sex } \\
\hline Male & $201(71.5)$ & $149(74.5)$ & $52(64.2)$ & \multirow[t]{2}{*}{0.083} \\
\hline Female & $80(28.5)$ & $51(25.5)$ & $29(35.8)$ & \\
\hline \multicolumn{5}{|l|}{ Ethnicity $^{a}$} \\
\hline Laothung & $269(95.7)$ & $192(96)$ & $77(95.1)$ & \multirow[t]{2}{*}{0.472} \\
\hline Other & $12(4.3)$ & $8(4)$ & $4(4.9)$ & \\
\hline \multicolumn{5}{|l|}{ Religion } \\
\hline Buddhist & $9(3.2)$ & $8(4)$ & $1(1.2)$ & \multirow[t]{2}{*}{0.213} \\
\hline Animist & $272(96.8)$ & $192(96)$ & $80(98.8)$ & \\
\hline \multicolumn{5}{|l|}{ Marital status } \\
\hline In relationship & $262(93.2)$ & $186(93)$ & $76(93.8)$ & \multirow[t]{2}{*}{0.518} \\
\hline Not in relationship & $19(6.8)$ & $14(7)$ & $5(6.2)$ & \\
\hline \multicolumn{5}{|l|}{ Literacy } \\
\hline Literate & $67(23.8)$ & $54(27)$ & $13(16)$ & \multirow[t]{2}{*}{0.051} \\
\hline Illiterate & $214(76.2)$ & $146(73)$ & $68(84)$ & \\
\hline \multicolumn{5}{|l|}{ Level of Education } \\
\hline Not attended school & $204(72.6)$ & $138(69)$ & $66(81.5)$ & \multirow[t]{2}{*}{0.034} \\
\hline Attended school & 77 (27.4) & $62(31)$ & $15(18.5)$ & \\
\hline \multicolumn{5}{|l|}{ Occupation } \\
\hline Farmer & $254(90.4)$ & $183(91.5)$ & $71(87.7)$ & \multirow[t]{2}{*}{0.322} \\
\hline Other & $27(9.6)$ & $17(8.5)$ & $10(12.3)$ & \\
\hline \multicolumn{5}{|l|}{ Monthly Income } \\
\hline$\leq 500,000 \mathrm{kip}(\leq 60$ USD) & $192(68.3)$ & $131(65.5)$ & $61(75.3)$ & \multirow[t]{4}{*}{0.007} \\
\hline 500,001 to $2,000,000$ kip (60 to 240 USD) & $41(14.6)$ & $33(16.5)$ & $8(9.9)$ & \\
\hline$\geq 2,000,001$ kip ( $\geq 240$ USD) & $27(9.6)$ & $25(12.5)$ & $2(2.5)$ & \\
\hline Don't know/NA & $21(7.5)$ & $11(52.4)$ & $10(12.3)$ & \\
\hline Daily Expense & & & & \\
\hline$\leq 1000$ kip $(\leq 0.12$ USD $)$ & $99(35.2)$ & $72(36)$ & $27(33.3)$ & 0.289 \\
\hline 1001 to 10,000 kip (0.12 to 1.18 USD) & $120(42.7)$ & $80(40)$ & $40(49.4)$ & \\
\hline$\geq 10,000$ kip ( $\geq 1.18$ USD) & $62(22.1)$ & $48(24)$ & $14(17.3)$ & \\
\hline
\end{tabular}


Table 2 Treatment seeking behaviour for febrile illnesses in relation to socio-economic characteristics of the participants $(n=281)$ (Continued)

\begin{tabular}{llll}
\hline Characteristics & $\begin{array}{l}\text { Total }(\mathrm{n}=281) \\
\text { Number }(\%)\end{array}$ & $\begin{array}{l}\text { Allopathic health services }(n=200) \\
\text { Number }(\%)\end{array}$ & $\begin{array}{l}\text { Non-allopathic health services }(n=81) \\
\text { Number }(\%)\end{array}$ \\
\hline $\begin{array}{llll}\text { Is the income enough to sustain living? } \\
\text { Yes }\end{array}$ & $82(29.2)$ & $52(26)$ & $30(37)$ \\
No & $198(70.5)$ & $148(74)$ & $50(61.7)$ \\
$\quad$ & $1(0.4)$ & & $1(1.2)$ \\
\hline
\end{tabular}

${ }^{a}$ Ka Tarng = 1 (0.4\%), Lao Loum = 3 (1.1\%), Mangkong = 200 (71.2\%), Phu Thai = 6 (2.1\%), Ta Oi = $3(1.1 \%)$, Tree = 64 (22.8\%), Vietnamese = $4(1.4 \%)$

Data recorded from observations highlighted how traditional healing consisted of mostly informal spiritual practices, specific to this religion. In general, traditional healers could be divided into spiritual healers and sorcerers. Spiritual healers were consulted for minor illnesses and were easily found. For more severe and chronic illnesses, such as repeated fever episodes or persistent weight-loss, sorcerers practising witchcraft were consulted. The sorcery healing aims to pacify disease-causing spirits by sacrificing animals such as pigs, chicken and cows. In all villages and sub-villages, traditional practitioners were respected and used alongside the allopathic health centres.

Community members also purchased over-the-counter medicines from authorized or unauthorized pharmacies, including, in Nong District, mobile drug vendors who visit from Vietnam. These drugs were commonly bought for minor complaints, such as headache, common cold and lower back pain. They are cheap treatment options compared to costs of visiting a health centre.

\section{Factors affecting treatment seeking at allopathic health facilities and general patterns of health seeking behaviour}

Almost three-quarters of participants $(72 \%, 201 / 281)$ reported having fallen sick or had fever in the past two months and more than 90\% of these participants (185/ 201) sought treatment. Half of the respondents $(49.1 \%$ $138 / 281)$ walked to the nearest health centre. A minority $(8 \%, 16 / 201)$ who did not seek treatment responded that they were either self-cured, took medicine from village health volunteers or from families or friends. Among those who sought treatment, $71 \%$ sought treatment at allopathic health services (200/281). Past health care seeking practices, such as visiting a health centre $(p<0.001)$, were associated with the reported preference for allopathic health services. Other factors such as distance to health centre $(\mathrm{p}<0.001)$, a good road to the health centre $(p=$ 0.002 ), and satisfaction with the services from health centre $(\mathrm{p}<0.001)$ were all associated with increased attendance at allopathic health services (Table 4).

Bivariate and multivariate logistic regression were conducted to explore independent factors associated with attendance at an allopathic health services. Respondents who belonged to the lowest income group $(\mathrm{AOR}=0.16$; $\mathrm{CI}=003$ to $0.76 ; p=0.02$ ), who had sought assistance from a spiritual healer or witch in the past $(\mathrm{AOR}=0.02$; $\mathrm{CI}=0.005$ to $0.08 ; \mathrm{p}<0.001)$ and who preferred medicine over-the-counter (AOR $=0.04 ; \mathrm{CI}=0.008$ to 0.22 ; $\mathrm{p}$ $<0.001)$ were less likely to attend allopathic health services. In contrast, participants who attended a health centre in the past $(\mathrm{AOR}=4.69 ; \mathrm{CI}=1.15$ to $19.06 ; p=$ 0.03 ) and who stayed nearest to the health centre (AOR $=6.5 ; \mathrm{CI}=1.74$ to $24.25 ; p=0.005)$ were more likely to attend an allopathic health services (Table 5).

These findings were further complemented by the qualitative data from focus group discussions and observational field notes. In line with quantitative data, qualitative methods bolstered how the barriers (cost of treatment, distance to the health centres and available means of transport) were embedded in their patterns of treatment seeking at various places (Fig. 2).

Villagers described a mental map where to seek care, depending upon the type of illness, and constraints to accessing the facility of choice, such as finances, distance to the facilities and the means of transportation. Respondents often reiterated the constraints, mostly the lack of cash money in these villages. The domestic cattle owned by the household were often the source of cash money and during emergency, depending upon the availability of cattle and the buyer, domestic cattle were sold for the cash. In addition to a high poverty in these villages, lack of cash money during emergency was a main barrier for visiting health centres.

I: Are there any reasons why someone in this community would not seek treatment?

FGD1S1: If the [villagers] do not have money [they will not go]. If they have, they will go.

FGD1S2: We do not have money [to go for the treatment].

(All others agreed).

I: Are there reasons why someone in this village would not seek treatment (for fever)?

FGD1S2: No money.

I: What about the transportation?

FGD1S2: Even if you have motorbike, if you don't (have) money for gasoline, you cannot go. 
Table 3 Treatment seeking behaviour for febrile illnesses in relation to household characteristics of the participants $(n=281)$

\begin{tabular}{|c|c|c|c|c|}
\hline \multirow[t]{2}{*}{ Characteristics } & Total $(n=281)$ & Allopathic health services $(n=200)$ & Non-allopathic health services $(n=81)$ & \multirow[t]{2}{*}{$p$-value } \\
\hline & Number (\%) & Number (\%) & \multirow{2}{*}{\multicolumn{2}{|c|}{ Number (\%) }} \\
\hline \multicolumn{3}{|c|}{ What do you own? ${ }^{\mathrm{a}}$} & & \\
\hline House & $281(100)$ & $200(71.2)$ & $81(28.8)$ & NA \\
\hline Land & $275(97.9)$ & $196(71.3)$ & $79(28.7)$ & 0.556 \\
\hline Motorbike & $153(54.4)$ & $106(69.3)$ & $47(30.7)$ & 0.263 \\
\hline Bicycle & $7(2.5)$ & $3(42.9)$ & $4(57.1)$ & 0.109 \\
\hline Tractor & $51(18.1)$ & $29(56.9)$ & $22(43.1)$ & 0.013 \\
\hline Cars & $4(1.4)$ & $3(75)$ & $1(25)$ & 0.673 \\
\hline Cattle & $118(42)$ & $87(73.7)$ & $31(26.3)$ & 0.421 \\
\hline TV & $53(18.9)$ & $38(71.7)$ & $15(28.3)$ & 0.926 \\
\hline Radio & $11(3.9)$ & $5(45.5)$ & $6(54.5)$ & 0.062 \\
\hline Phones & $122(43.4)$ & $91(74.6)$ & $31(25.4)$ & 0.165 \\
\hline \multicolumn{5}{|c|}{ What are your walls of your home made from? ${ }^{a}$} \\
\hline Bamboo & $126(44.8)$ & $94(74.6)$ & $32(25.4)$ & 0.253 \\
\hline Wood & $189(67.3)$ & $128(67.7)$ & $61(32.3)$ & 0.067 \\
\hline Concrete & $1(0.4)$ & 0 & 1 & 0.288 \\
\hline Plastic & $10(3.6)$ & $7(70)$ & $3(30)$ & 0.588 \\
\hline Metal & $8(2.8)$ & $3(37.5)$ & $5(62.5)$ & 0.047 \\
\hline \multicolumn{5}{|c|}{ What is the roof of your home made from? ${ }^{\mathrm{a}}$} \\
\hline Bamboo & $21(7.5)$ & $16(76.2)$ & $5(23.8)$ & 0.402 \\
\hline Wood & $4(1.4)$ & $3(75)$ & $1(25)$ & 0.673 \\
\hline Plastic & $5(1.8)$ & $5(100)$ & 0 & 0.18 \\
\hline Metal & $212(75.4)$ & $147(69.3)$ & $65(30.7)$ & 0.234 \\
\hline Shingles & $53(18.9)$ & $41(77.4)$ & $12(22.6)$ & 0.175 \\
\hline \multicolumn{5}{|c|}{ What is the floor of your home made from? $?^{a}$} \\
\hline Bamboo & $44(15.7)$ & $31(70.5)$ & $13(29.5)$ & 0.909 \\
\hline Wood & $251(89.3)$ & $181(72.1)$ & $70(27.9)$ & 0.212 \\
\hline Mud & $2(0.7)$ & $2(100)$ & 0 & 0.506 \\
\hline Concrete & $8(2.8)$ & $3(37.5)$ & $5(62.5)$ & 0.047 \\
\hline \multicolumn{5}{|c|}{ Do you have toilet facility at home? } \\
\hline Yes & $22(7.8)$ & $14(7)$ & $8(9.9)$ & 0.279 \\
\hline No & $259(92.2)$ & $186(93)$ & $73(90.1)$ & \\
\hline \multicolumn{5}{|c|}{ Did you migrate from any other village? } \\
\hline Yes & $61(21.7)$ & $43(21.5)$ & $18(22.2)$ & 0.894 \\
\hline No & $220(78.3)$ & $157(78.5)$ & $63(77.8)$ & \\
\hline \multicolumn{5}{|c|}{ If Yes how long have you been living here? } \\
\hline$\leq 10$ years & $28(45.9)$ & $18(41.9)$ & $10(55.6)$ & 0.617 \\
\hline $11-20$ years & $17(27.9)$ & $13(30.2)$ & $4(22.2)$ & \\
\hline$\geq 21$ years & $16(26.2)$ & $12(27.9)$ & $4(22.2)$ & \\
\hline \multicolumn{5}{|c|}{ How far is the forest from your house in $\mathrm{km}$ ? } \\
\hline$\leq 1 \mathrm{~km}$ & $97(34.5)$ & $57(28.5)$ & $40(49.4)$ & 0.007 \\
\hline 1.1 to $2 \mathrm{~km}$ & $76(27)$ & $62(31)$ & $14(17.3)$ & \\
\hline$\geq 2.1 \mathrm{~km}$ & $49(17.4)$ & $37(18.5)$ & $12(14.8)$ & \\
\hline NA & $59(21)$ & $44(22)$ & $15(18.5)$ & \\
\hline
\end{tabular}


Table 3 Treatment seeking behaviour for febrile illnesses in relation to household characteristics of the participants $(n=281$ ) (Continued)

\begin{tabular}{|c|c|c|c|c|}
\hline \multirow[t]{2}{*}{ Characteristics } & Total $(n=281)$ & Allopathic health services $(n=200)$ & Non-allopathic health services $(n=81)$ & \multirow[t]{2}{*}{$p$-value } \\
\hline & Number (\%) & Number (\%) & Number (\%) & \\
\hline \multicolumn{5}{|c|}{ How far is the forest from your house in min? } \\
\hline$\leq 7 \mathrm{~min}$ & 19 (34.5) & $16(39)$ & $3(21.4)$ & \multirow[t]{3}{*}{0.442} \\
\hline 7.1 to $60 \mathrm{~min}$ & $21(38.2)$ & $14(34.1)$ & $7(50)$ & \\
\hline$\geq 61 \mathrm{~min}$ & $15(27.3)$ & $11(26.8)$ & $4(28.6)$ & \\
\hline \multicolumn{5}{|c|}{ How far is your rice field from your house in $\mathrm{km}$ ? } \\
\hline$\leq 1 \mathrm{~km}$ & $75(26.7)$ & $56(28)$ & $19(23.5)$ & \multirow[t]{4}{*}{0.331} \\
\hline 1.1 to $2 \mathrm{~km}$ & $84(29.9)$ & $64(32)$ & $20(24.7)$ & \\
\hline$\geq 2.1 \mathrm{~km}$ & $56(19.9)$ & $36(18)$ & $20(24.7)$ & \\
\hline NA/Not own Land & $66(23.5)$ & $44(22)$ & $22(27.2)$ & \\
\hline \multicolumn{5}{|c|}{ How far is your rice field from your house in Min? } \\
\hline$\leq 20 \min$ & $18(33.3)$ & $13(35.1)$ & $5(29.4)$ & \multirow[t]{3}{*}{0.577} \\
\hline 21 to $60 \mathrm{~min}$ & $30(55.6)$ & $21(56.8)$ & $9(52.9)$ & \\
\hline$\geq 61 \mathrm{~min}$ & $6(11.1)$ & $3(8.1)$ & $3(17.6)$ & \\
\hline \multicolumn{5}{|c|}{ How often do you go to forest? } \\
\hline Everyday & $171(60.9)$ & $126(63)$ & $45(55.6)$ & \multirow[t]{3}{*}{0.441} \\
\hline Every Alternate Day & $68(24.2)$ & $47(23.5)$ & $21(30.9)$ & \\
\hline$\geq$ Weekly & $42(14.9)$ & $27(13.5)$ & $15(18.5)$ & \\
\hline
\end{tabular}

ancludes only "yes" answers and since multiple answers were possible, percentage do not add to 100

FGD with eight female participants in "Oi" sub-village of OTP.

For mild illnesses (e.g. cold), community members often sought assistance from village health volunteers in addition to buying medicine over-the-counter or taking traditional remedies or herbs, which are prevalent in the villages (Fig. 2). For mild to moderate illnesses, respondents were likely to first attend traditional healers and then allopathic health services (health centres). If villagers recognized specific diseases, such as malaria, diarrhoea and respiratory illnesses, they were more likely to attend a health centre. Respondents described being more likely to attend traditional healers (spiritual healers and sorcerers) if they felt the response at the allopathic health services was not satisfactory. Decisions were also influenced by the household members, village head and the traditional healers. Sometimes, respondents described their reasons for visiting traditional healers as embedded in their cultural practices. Often the driving factors for following these traditions were mentioned to be rooted to their animist religion.

I: When you were sick, where did all of you go for treatment?

FGD11S1: Hospital (Health centre).

I: Did you go to the spiritual healer (Yao)?

FGD11S1: Yes, I did. We always do [Yao] first before we go to hospital because this is our culture [tradition].

I: What about witchcraft (Mor Pao)?
FGD11S1: We go, if we are very sick.

I: The spiritual healer and witch is the same person or not?

FGD11S1: No! It is not same.

FGD with eight female participants in Xuang Tai.

Community members described how their choices were often constrained by money at each stage: Respondents described how visiting spiritual healers was more frequent and more economical than visiting sorcerers who were often reserved for moderate to severe illnesses. Money, distance and a lack of appropriate transport were reported as barriers to accessing allopathic health (services) centres. The prominence of the barriers increased if respondents wanted to visit tertiary health centres (e.g. the district hospital, provincial hospital and hospital across the border). Respondents described eloquently how their subsequent visits to higher health centres if failed to cure them forced them to "return home and wait for death".

I: If somebody feels sick (malaria) in your village, where do they normally go for treatment??

FGD2S1: Danvilay health centre.

FGD2S2: I will buy medicine with village health volunteer.

FGD2S3: Danvilay health centre.

FGD2S5: I will treat (seek treatment) with village health volunteer if it does not work I will go to health centre. 
Table 4 Treatment seeking behaviour for febrile illnesses in relation to health center and past behaviour $(n=281)$

\begin{tabular}{|c|c|c|c|c|}
\hline \multirow[t]{2}{*}{ Characteristics } & Total $(n=281)$ & Allopathic health services $(n=200)$ & Non-allopathic health services $(n=81)$ & \multirow[t]{2}{*}{$p$-value } \\
\hline & Number (\%) & Number (\%) & Number (\%) & \\
\hline \multicolumn{5}{|c|}{ Have you ever become sick or had fever in the past 2 months? } \\
\hline Yes & $201(71.5)$ & $143(71.5)$ & $58(71.6)$ & \multirow[t]{2}{*}{0.986} \\
\hline No & $80(28.5)$ & $57(28.5)$ & $23(28.4)$ & \\
\hline \multicolumn{5}{|c|}{ If Yes, did you seek treatment? $(n=201)$} \\
\hline Yes & $185(92)$ & $134(93.7)$ & $51(87.9)$ & \multirow[t]{2}{*}{0.14} \\
\hline No & $16(8)$ & $9(6.3)$ & $7(12.1)$ & \\
\hline \multicolumn{5}{|c|}{ If Yes, where did you first seek treatment? $(n=185)$} \\
\hline \multicolumn{5}{|l|}{ Self-treatment } \\
\hline No & $184(99.5)$ & $134(100)$ & $50(98)$ & \multirow[t]{2}{*}{0.276} \\
\hline Yes & $1(0.5)$ & 0 & $1(2)$ & \\
\hline \multicolumn{5}{|l|}{ Sorcerer } \\
\hline No & $137(74.1)$ & $123(91.8)$ & $14(27.5)$ & \multirow[t]{2}{*}{$<0.001$} \\
\hline Yes & $48(25.9)$ & $11(8.2)$ & $37(72.5)$ & \\
\hline \multicolumn{5}{|l|}{ Health center } \\
\hline No & $36(19.5)$ & $14(10.4)$ & $22(43.1)$ & \multirow[t]{2}{*}{$<0.001$} \\
\hline Yes & $149(80.5)$ & $120(89.6)$ & $29(56.9)$ & \\
\hline \multicolumn{5}{|l|}{ Other } \\
\hline No & $167(90.3)$ & $121(90.3)$ & $46(90.2)$ & \multirow[t]{2}{*}{0.588} \\
\hline Yes & $18(9.7)$ & $13(9.7)$ & $5(9.8)$ & \\
\hline \multicolumn{5}{|c|}{ Which do you prefer more between? } \\
\hline Lao Traditional Medicine & $4(1.4)$ & $3(1.5)$ & $1(1.2)$ & \multirow[t]{3}{*}{0.023} \\
\hline Allopathic Health Services & $274(97.5)$ & $197(98.5)$ & $77(95.1)$ & \\
\hline NA & $3(1.1)$ & 0 & $3(3.7)$ & \\
\hline \multicolumn{5}{|c|}{ How far is the nearest health center from your home in $\mathrm{km}$ ? } \\
\hline$\leq 3.5 \mathrm{~km}$ & $94(33.5)$ & $84(42)$ & $10(12.3)$ & \multirow[t]{3}{*}{$<0.001$} \\
\hline 3.6 to $12 \mathrm{~km}$ & $99(35.2)$ & $67(33.5)$ & $32(39.5)$ & \\
\hline$\geq 12.1 \mathrm{~km}$ & $88(31.3)$ & $49(24.5)$ & $39(48.1)$ & \\
\hline \multicolumn{5}{|c|}{ How far is the nearest health center from your home in min? } \\
\hline$\leq 30 \min$ & 49 (63.6) & $22(52.4)$ & $27(77.1)$ & \multirow[t]{3}{*}{0.065} \\
\hline$\geq 31 \mathrm{~min}$ & $26(33.8)$ & $19(45.2)$ & $7(20)$ & \\
\hline NA & $2(2.6)$ & $1(2.4)$ & $1(2.9)$ & \\
\hline \multicolumn{5}{|c|}{ How do you get to the health center/hospital? } \\
\hline By walk & $138(49.1)$ & $97(48.5)$ & $41(50.6)$ & \multirow[t]{3}{*}{0.002} \\
\hline By some means & $136(48.4)$ & $102(51)$ & $34(42)$ & \\
\hline NA & $7(2.5)$ & $1(0.5)$ & $6(7.4)$ & \\
\hline Is the road to nearest health & er in good condit & & & \\
\hline Yes & $214(76.2)$ & $157(78.5)$ & $57(70.4)$ & 0.002 \\
\hline No & $62(22.1)$ & $43(21.5)$ & $19(23.5)$ & \\
\hline Don't know & $5(1.8)$ & 0 & $5(6.2)$ & \\
\hline Are you satisfied with your ne & t health center? & & & \\
\hline Yes & $261(92.9)$ & $192(96)$ & $69(85.2)$ & $<0.001$ \\
\hline No & $8(2.8)$ & $6(3)$ & $2(2.5)$ & \\
\hline Don't know & $12(4.3)$ & $2(1)$ & $10(12.3)$ & \\
\hline
\end{tabular}


Table 4 Treatment seeking behaviour for febrile illnesses in relation to health center and past behaviour $(n=281)($ Continued)

\begin{tabular}{|c|c|c|c|c|}
\hline \multirow[t]{2}{*}{ Characteristics } & Total $(n=281)$ & Allopathic health services $(n=200)$ & Non-allopathic health services $(n=81)$ & \multirow[t]{2}{*}{$p$-value } \\
\hline & Number (\%) & Number (\%) & Number (\%) & \\
\hline \multicolumn{5}{|c|}{ Can you get medicine on the counter? } \\
\hline Yes & $85(30.2)$ & $70(35)$ & $15(18.5)$ & \multirow[t]{3}{*}{$<0.001$} \\
\hline No & $188(66.9)$ & $129(64.5)$ & $59(72.8)$ & \\
\hline Don't know & $8(2.8)$ & $1(0.5)$ & $7(8.6)$ & \\
\hline \multicolumn{5}{|c|}{ Do you prefer on the counter medicine? } \\
\hline Yes & $23(8.2)$ & $12(6)$ & $11(13.6)$ & \multirow[t]{3}{*}{0.001} \\
\hline No & $246(87.5)$ & $184(92)$ & $62(76.5)$ & \\
\hline Don't know & $12(4.3)$ & $4(2)$ & $8(9.9)$ & \\
\hline \multicolumn{5}{|l|}{ If Yes, Why? } \\
\hline \multicolumn{5}{|c|}{ Because it is easy } \\
\hline No & $5(21.7)$ & $5(41.7)$ & 0 & \multirow[t]{2}{*}{0.024} \\
\hline Yes & $18(78.3)$ & $7(58.3)$ & $11(100)$ & \\
\hline \multicolumn{5}{|c|}{ I don't like to go to health center } \\
\hline No & $22(95.7)$ & $11(91.7)$ & $11(100)$ & \multirow[t]{2}{*}{0.522} \\
\hline Yes & $1(4.3)$ & $1(8.3)$ & 0 & \\
\hline \multicolumn{5}{|l|}{ It is faster } \\
\hline No & $15(65.2)$ & $9(75)$ & $6(54.5)$ & \multirow[t]{2}{*}{0.278} \\
\hline Yes & $8(34.8)$ & $3(25)$ & $5(45.5)$ & \\
\hline \multicolumn{5}{|l|}{ It is cheaper } \\
\hline No & $22(95.7)$ & $12(100)$ & $10(90.9)$ & \multirow[t]{2}{*}{0.478} \\
\hline Yes & $1(4.3)$ & 0 & $1(9.1)$ & \\
\hline \multicolumn{5}{|c|}{ Because doctors do not prescribe } \\
\hline No & $21(91.3)$ & $10(83.3)$ & $11(100)$ & \multirow[t]{2}{*}{0.261} \\
\hline Yes & $2(8.7)$ & $2(16.7)$ & 0 & \\
\hline \multicolumn{5}{|l|}{ Other } \\
\hline No & $22(95.7)$ & $11(91.7)$ & $11(100)$ & \multirow[t]{2}{*}{0.522} \\
\hline Yes & $1(4.3)$ & $1(8.3)$ & 0 & \\
\hline \multicolumn{5}{|l|}{ NA } \\
\hline No & $21(91.3)$ & $10(83.3)$ & $11(100)$ & \multirow[t]{2}{*}{0.261} \\
\hline Yes & $2(8.7)$ & $2(16.7)$ & 0 & \\
\hline
\end{tabular}

FGD2S1: if the health centre does not work I will go to District hospital, if the district hospital does not work I will go to Savannakhet hospital, if Savannakhet hospital does not work I will come back home and wait to die.

FGD with eight male participants at "Oi" sub-village of OTP.

\section{Discussion}

This is the first study to report the treatment seeking behaviours for febrile illness in remote villages in one of the poorest district of Lao PDR with a predominantly minority Lao Theung population.

In remote villages of Laos, respondents highlighted several barriers to seeking treatment at allopathic health services: the absence of cash, distance to health care services, absence of transport, the availability of traditional healing practices and the expected costs of health centre visits $[15,26,28,29,32,42,43]$. Participants with low income were less likely to attend allopathic health services and this reflects the impact of income on health seeking that has been reported in other areas of Laos [26, 27, 30-34].

Cash to pay for treatment came from the sale of domestic animals, such as cows, pigs, goats, chicken and buffaloes. However, during an emergency, it was often impossible to sell domestic animals in a short period of time. The mobile merchants on whom community members depended to make a sale come at 
Table 5 Logistic regression analysis to identify independently significant variables associated with treatment seeking at Allopathic health services for febrile illnesses

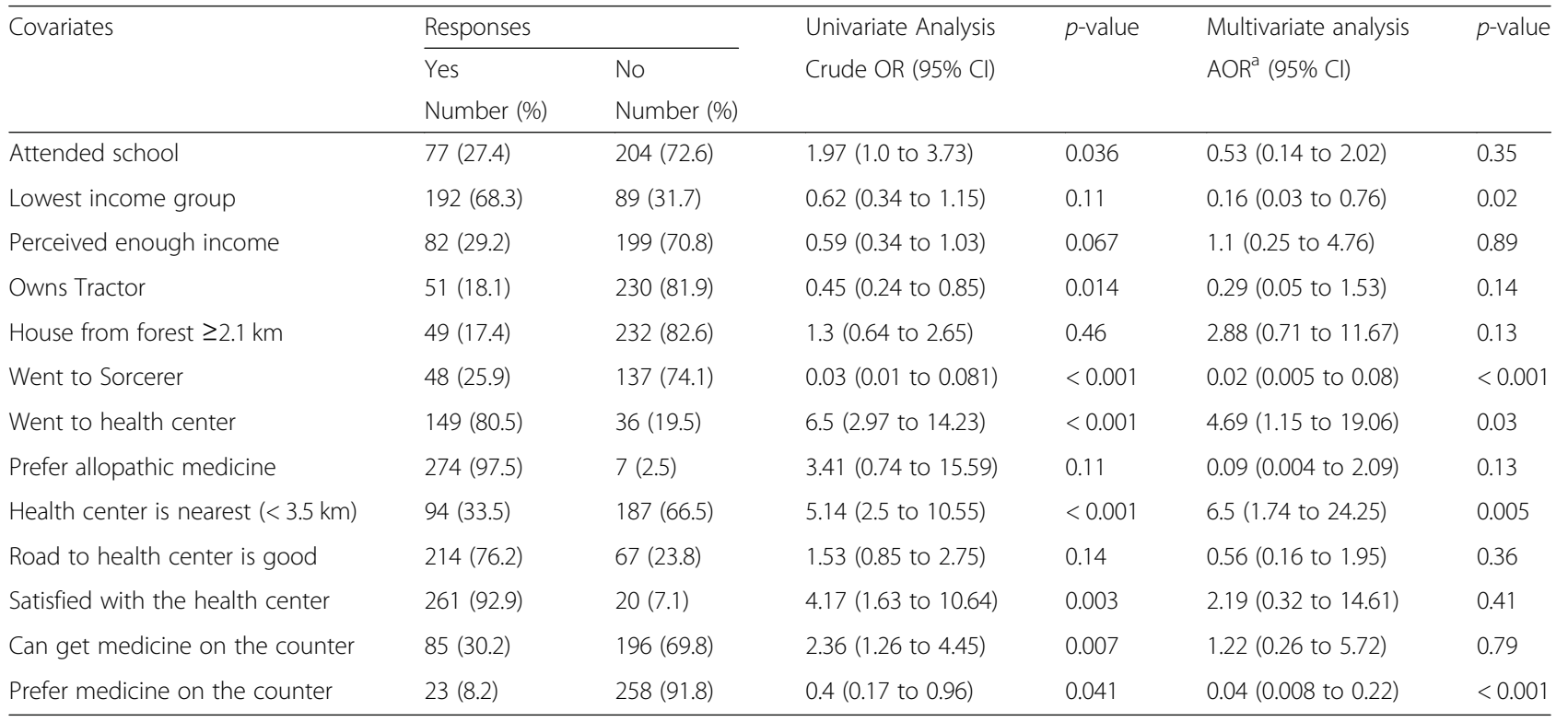

${ }^{a}$ Adjusted for variables age and sex

unpredictable intervals from Vietnam. This is also specific for Nong District, which borders Vietnam [24]. Economic constraints have been described as a major determinant in many low-income countries for seeking health care, including studies from Cambodia [15, 43, 44], Uganda [39] and Bangladesh [45]. Participants with lower income reported underutilization of allopathic health services, delaying the treatment seeking because often the cost of health care exceeded their monthly income which is classified as catastrophic expenditure (>25\% of monthly household income).

Proximity of the household to the health centre was found to be an important determinant of allopathic health care utilisation. In addition, factors such as lack of public transport, motorbikes, price of fuel and road conditions were associated barriers to attending health centres in Laos. Distance to health centre is a well-established determinant of care utilisation in Laos [26, 27, 29]. In Cambodia, distance to health centre was perceived as a major determinant of health service attendance [43, 44]. Similarly, in Uganda, distance to health centre was found to affect the uptake of health services [39]. In Nepal, longer distance and longer travel time were found to be associated with higher cost and recognized as a barrier for attending health centres [46]. In Nigeria, delay in attending health centre was associated with longer walking distance to the health centre [47].

Remote villages are also the hotspots for malaria transmission [3]. In such villages, allopathic health centres were popular sources of care for febrile illness, but community members' access to these services was affected by their socio-economic status and the lack of local infrastructure. Improving essential infra-structures, particularly roads and public transportation, is needed to improve accessibility. However, the remoteness of these villages presents significant challenges to infrastructure development. Building the capacity of existing local village volunteers (village malaria workers) with additional training and strengthening their involvement with the malaria control program has been suggested by a recent study in Cambodia to mitigate barriers to accessing health services to expedite the malaria elimination [48].

As in many settings, in Nong District, respondents described how traditional healers are deeply rooted to local culture and customs $[49,50]$. In the study villages, a mix of practices was described, with the preferred source of treatment influenced by illness severity, economic status and road conditions. Decisions were often influenced by the opinions of other household members, the village head, and traditional healers [12, 24, 41]. A mix of traditional and allopathic medicine has been described in past studies from Laos [51], Kenya [52] and Uganda [53]. Given their prominence and the respect that they garner in the community, malaria control programmes should consider collaborating with traditional healers as a means to strengthen their links to communities. A recent scoping review has also highlighted how peripheral health care in Laos can be strengthened by collaborating with both formal and informal health care providers for malaria elimination [8].

Amongst community members who participated in the questionnaire, more than a third of respondents were likely to seek over-the-counter medication. Popular for minor complaints, such as headache, common cold and low back pain, they are attractive options particularly because of the costs associated with visiting a district hospital or health 


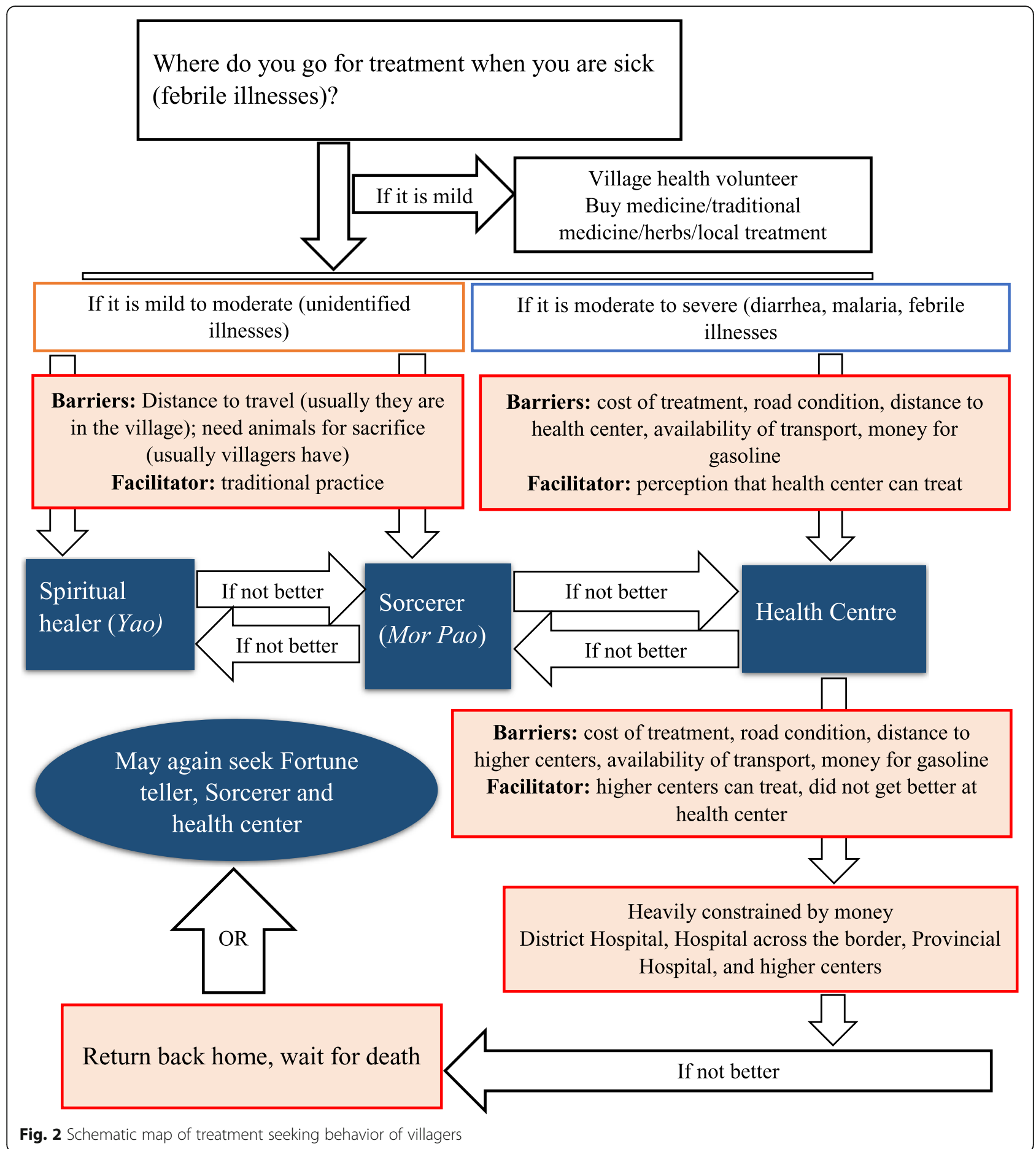

centre. Since the 1960s [54], medicines have been purchased from authorized or unauthorized pharmacies, including, in Nong District, mobile drug vendors who visit from Vietnam [32].

\section{Strengths and limitation}

This study used qualitative and quantitative methods for data collection. Three researchers collected data to reduce the possibility of personal bias caused by the influence of a single data collector. Cultural modesty and conformism including social desirability bias may have affected the data from FGDs and questionnaire. The findings are limited by the fact that this study took place as a baseline and formative research to inform and guide the community engagement and TME. However, we think our results are representative of the health seeking behaviour of the study 
population and can inform current and future malaria control programmes in Savannakhet, Lao PDR. This study derived the data from on-site translation from bilingual translators who were fluent in Lao and local Lao Theung language. The Lao Theung language spoken by the minority groups has no written script, some nuances and meaning could have been lost during translation. This study is also limited by the fact that health-seeking behaviour were explored in terms of febrile illnesses. Nevertheless, future studies can build on these findings to explore the overall treatment seeking behaviour for febrile illnesses, determinants of attending health services and the contribution to development of antimicrobial resistance both within Laos and outside. Respondents were asked about their past febrile illnesses in last two months and how they responded to it. Although two-months period provided respondents an adequate time to recall their febrile illnesses and pertinent past health seeking behaviour, their responses could have incurred recall bias. However, there were follow-up questions to past febrile illnesses in terms of where they sought treatment, this helped to minimize the recall errors.

\section{Conclusion}

Treatment for febrile illness was sought from allopathic health centres and traditional practitioners, depending upon the severity of symptoms, availability of cash, distance to health centre, road conditions, and the availability of transport. In spite of these barriers, health centres were the preferred choice for treatment. Improvements in local infrastructure would probably help to overcome some of these issues but are likely to take time and considerable investment. In light of redoubled efforts to eliminate malaria, however, at least in the short-term, less costly options include strengthening the network of village health volunteers and involving traditional healers. These groups are easily accessible to community members and their roles in malaria control strategies could be strengthened through training and by formalizing their links with these programmes.

\section{Abbreviations}

AOR: Adjusted Odds Ratio; API: Annual Parasite Index; Cl: 95\% Confidence Interval; FGDs: Focus Group Discussions; GMS: Greater Mekong Sub-region; LLINs: Long Lasting Insecticide Nets; MDA: Mass Drug (antimalarial)

Administration; ODK: Open Data Kit; OTP: Oi Tan Tip village; PCR: Polymerase Chain Reaction; PDR: People's Democratic Republic; PMM: Phoun Mak Mee village; TME: Targeted Malaria Elimination; TT: Tha Thay village; uPCR: ultrasensitive Polymerase Chain Reaction; USD: United States Dollar; VMW: Village Malaria Worker; XT: Xuang Tai village

\section{Acknowledgements}

We would like to thank the respondents who generously participated in the study. We would like to acknowledge all the staff and volunteers who contributed in TME. We are also grateful to staffs and authorities who contributed in TME at Nong from LOMWRU (Lao-Oxford-Mahosot Hospital-Wellcome Trust Research Unit), CMPE (Centre of Malariology, Parasitology and Entomology), Savannakhet
Provincial Health Department, Nong District Health Department and local health centers.

\section{Funding}

This study was funded by the Bill and Melinda Gates Foundation and the Wellcome Trust. The Lao-Oxford-Mahosot Hospital-Wellcome Trust Research Unit and the Mahidol Oxford Tropical Medicine Research Unit are funded by the Wellcome Trust. The funders had no role in study design, data collection and analysis, decision to publish, or preparation of the manuscript.

\section{Availability of data and materials}

The data is available upon request to the Mahidol Oxford Tropical Medicine Research Unit Data Access Committee (http://www.tropmedres.ac/datasharing) complying with the data access policy (http://www.tropmedres.ac/ asset/file/data-sharing-policy-v1-0.pdf). Queries and applications for datasets should be directed to Rita Chanviriyavuth (rita@tropmedes.ac).

\section{Authors' contributions}

Conceptual design of the study: BA, MM, CP, PYC and LvS; Questionnaire design, data collection methods, analysis and revision: BA, MM, LVS, GH, PS, KP, XS, PK, DMP; FGDs guide: CP, BA, MM; Overall supervision: AMD, NJW, NPJD, PNN, LVS, MM, TP. All authors read and approved the final proof.

\section{Ethics approval and consent to participate}

Ethical approval for the study was received from the Lao National Ethics Committee for Health Research (Ref. No. 013-2015/NECHR), Government of the Lao PDR and the Oxford Tropical Research Ethics Committee (1015-13). Written informed consent were sought from each participant before each interview.

Consent for publication

Not applicable.

\section{Competing interests}

The authors declare that they have no competing interests.

\section{Publisher's Note}

Springer Nature remains neutral with regard to jurisdictional claims in published maps and institutional affiliations.

\section{Author details}

${ }^{1}$ Mahidol-Oxford Tropical Medicine Research Unit, Faculty of Tropical Medicine, Mahidol University, Bangkok, Thailand. ${ }^{2}$ Centre for Tropical Medicine and Global Health, Nuffield Department of Medicine, University of Oxford, Oxford, UK. ${ }^{3}$ Kellogg College, University of Oxford, Oxford, UK. ${ }^{4}$ Lao-Oxford-Mahosot Hospital-Wellcome Trust Research Unit (LOMWRU), Microbiology Laboratory, Mahosot Hospital, Vientiane, Laos. ${ }^{5}$ Savannakhet Provincial Health Department, SavannakhetProvinceLaos. ${ }^{6}$ Faculty of Infectious and Tropical Diseases, London School of Hygiene and Tropical Medicine, Keppel Street, London, UK. ${ }^{7}$ Department of Population Health and Disease Prevention, University of California, Irvine, California, USA. ${ }^{8}$ The Ethox Centre, Nuffield Department of Population Health, University of Oxford, Oxford, UK. ${ }^{9}$ Centre for Social Science and Global Health, University of Amsterdam, Amsterdam, The Netherlands. ${ }^{10}$ Amsterdam Institute for Global Health and Development, Amsterdam, The Netherlands. ${ }^{11}$ Institute of Research and Educational Development, University of Health Sciences, Vientiane, Laos.

Received: 13 October 2018 Accepted: 8 April 2019

Published online: 24 April 2019

References

1. WHO: Eliminating malaria in the Greater Mekong Sub-region (Available online: http://apps.who.int/iris/bitstream/10665/251668/1/WHO-HTM-GMP2016.12-eng.pdf?ua=1) (Accessed online 22nd February, 2018). 2016.

2. Chen I, Thanh HNT, Lover A, Thao PT, Luu TV, Thang HN, Thang ND, Neukom J, Bennett A. Malaria risk factors and care-seeking behaviour within the private sector among high-risk populations in Vietnam: a qualitative study. Malar J. 2017;16(1):414.

3. Phommasone $K$, Adhikari $B$, Henriques $G$, Pongvongsa $T$, Phongmany $P$, von Seidlein L, White NJ, Day NP, MD A, Newton PN, et al. Asymptomatic 
Plasmodium infections in 18 villages of southern Savannakhet Province, Lao PDR (Laos). Malar J. 2016;15(1):296.

4. Peeters Grietens K, Xuan XN, Van Bortel W, Duc TN, Ribera JM, Ba Nhat T, Van KP, Le Xuan H, D'Alessandro U, Erhart A. Low perception of malaria risk among the Ra-glai ethnic minority in south-Central Vietnam: implications for forest malaria control. Malar J. 2010;9:23.

5. Peeters Grietens K, Gryseels C, Dierickx S, Bannister-Tyrrell M, Trienekens S, Uk S, Phoeuk P, Suon S, Set S, Gerrets R, et al. Characterizing types of human mobility to inform differential and targeted malaria elimination strategies in Northeast Cambodia. Sci Rep. 2015;5:16837.

6. Gryseels C, Peeters Grietens K, Dierickx S, Xuan XN, Uk S, Bannister-Tyrrell M, Trienekens S, Ribera JM, Hausmann-Muela S, Gerrets R, et al. High mobility and low use of malaria preventive measures among the Jarai male youth along the Cambodia-Vietnam border. Am J Trop Med Hyg. 2015;93(4):810-8.

7. Gryseels C, Durnez L, Gerrets R, Uk S, Suon S, Set S, Phoeuk P, Sluydts V, Heng S, Sochantha T, et al. Re-imagining malaria: heterogeneity of human and mosquito behaviour in relation to residual malaria transmission in Cambodia. Malar J. 2015;14:165.

8. Kounnavong S, Gopinath D, Hongvanthong B, Khamkong C, Sichanthongthip O. Malaria elimination in Lao PDR: the challenges associated with population mobility. Infectious diseases of poverty. 2017;6(1):81.

9. Adhikari B, Phommasone K, Pongvongsa T, Soundala X, Koummarasy P, Henriques G, Peto TJ, Seidlein LV, White NJ, Day NPJ, et al. Perceptions of asymptomatic malaria infection and their implications for malaria control and elimination in Laos. PLoS One. 2018;13(12):e0208912.

10. Pongvongsa T, Phommasone K, Adhikari B, Henriques G, Chotivanich K, Hanboonkunupakarn B, Mukaka M, Peerawaranun P, von Seidlein L, Day NPJ, et al. The dynamic of asymptomatic Plasmodium falciparum infections following mass drug administrations with dihydroarteminisin-piperaquine plus a single low dose of primaquine in Savannakhet Province, Laos. Malar J. 2018;17(1):405.

11. von Seidlein L, Dondorp A. Fighting fire with fire: mass antimalarial drug administrations in an era of antimalarial resistance. Expert Rev Anti-Infect Ther. 2015;13(6):715-30.

12. Adhikari B, Phommasone K, Pongvongsa T, Kommarasy P, Soundala X, Henriques G, White NJ, Day NPJ, Dondorp AM, von Seidlein L, et al. Factors associated with population coverage of targeted malaria elimination (TME) in southern Savannakhet Province, Lao PDR. Malar J. 2017;16(1):424.

13. von Seidlein $L$, Peto TJ, Landier J, Nguyen TN, Tripura R, Phommasone $K$, Pongvongsa T, Lwin KM, Keereecharoen L, Kajeechiwa L, et al. The impact of targeted malaria elimination with mass drug administrations on falciparum malaria in Southeast Asia: a cluster randomised trial. PLoS Med. 2019;16(2):e1002745.

14. Guyant P, Corbel V, Guerin PJ, Lautissier A, Nosten F, Boyer S, Coosemans M, Dondorp AM, Sinou V, Yeung $S$, et al. Past and new challenges for malaria control and elimination: the role of operational research for innovation in designing interventions. Malar J. 2015;14:279.

15. Gryseels C, Uk S, Erhart A, Gerrets R, Sluydts V, Durnez L, Muela Ribera J, Hausmann Muela S, Menard D, Heng S, et al. Injections, cocktails and diviners: therapeutic flexibility in the context of malaria elimination and drug resistance in Northeast Cambodia. PLoS One. 2013;8(11):e80343.

16. Kaehler N, Adhikari B, Cheah PY, Day NPJ, Paris DH, Tanner M, Pell C. The promise, problems and pitfalls of mass drug administration for malaria elimination: a qualitative study with scientists and policymakers. Int Health. 2018.

17. Nofal SD, Peto TJ, Adhikari B, Tripura R, Callery J, Bui TM, von Seidlein L, Pell C. How can interventions that target forest-goers be tailored to accelerate malaria elimination in the greater Mekong subregion? A systematic review of the qualitative literature. Malar J. 2019;18(1):32.

18. Bruxvoort K, Goodman C, Kachur SP, Schellenberg D. How patients take malaria treatment: a systematic review of the literature on adherence to antimalarial drugs. PLoS One. 2014;9(1):e84555.

19. Atkinson JA, Fitzgerald L, Toaliu H, Taleo G, Tynan A, Whittaker M, Riley I, Vallely A. Community participation for malaria elimination in Tafea Province. Vanuatu: Part I Maintaining motivation for prevention practices in the context of disappearing disease Malaria journal. 2010;9:93.

20. Atkinson JA, Vallely A, Fitzgerald $L$, Whittaker $M$, Tanner $M$. The architecture and effect of participation: a systematic review of community participation for communicable disease control and elimination. Implications for malaria elimination Malaria journal. 2011;10:225.

21. Adhikari B, James N, Newby G, von Seidlein L, White NJ, Day NP, Dondorp AM, Pell C, Cheah PY. Community engagement and population coverage in mass anti-malarial administrations: a systematic literature review. Malar J. 2016;15(1):523.

22. Heggenhougen HK, Hackethal V, Vivek P. The behavioural and social aspects of malaria and its control: an introduction and annotated biliography. Geneva, Switzerland: World Health Organization; 2003.

23. Makoge V, Maat H, Vaandrager L, Koelen M. Health-seeking behaviour towards poverty-related disease (PRDs): a qualitative study of people living in camps and on campuses in Cameroon. PLoS Negl Trop Dis. 2017;11(1):e0005218.

24. Adhikari B, Pell C, Phommasone K, Soundala X, Kommarasy P, Pongvongsa T, Henriques G, Day NPJ, Mayxay M, Cheah PY. Elements of effective community engagement: lessons from a targeted malaria elimination study in Lao PDR (Laos). Glob Health Action. 2017;10(1):1366136.

25. Pell CL, Adhikari B, Myo Thwin M, Kajeechiwa L, Nosten S, Nosten FH, Sahan KM, Smithuis FM, Nguyen TN, Hien TT, et al. Community engagement, social context and coverage of mass anti-malarial administration: comparative findings from multi-site research in the greater Mekong sub-region. PLoS One. 2019;14(3):e0214280

26. Ngan Do K, Kang M, Lee C, Vanphanom S. Back to Basics Approach for Improving Maternal Health Care Services Utilization in Lao PDR. Asia Pac J Public Health. 2016;28(3):244-52.

27. Sychareun V, Phommachanh S, Soysouvanh S, Lee C, Kang M, Oh J, Durham J. Provider perspectives on constraints in providing maternal, neonatal and child health services in the Lao People's democratic republic: a qualitative study. BMC Pregnancy Childbirth. 2013;13:243.

28. Phrasisombath K, Thomsen S, Sychareun V, Faxelid E. Care seeking behaviour and barriers to accessing services for sexually transmitted infections among female sex workers in Laos: a cross-sectional study. BMC Health Serv Res. 2012;12:37.

29. Mayxay M, Hansana V, Sengphilom B, Oulay L, Thammavongsa V, Somphet V, Taykeophithoune C, Nathavong S, Phanthady J, Chareunvong K, et al. Respiratory illness healthcare-seeking behavior assessment in the Lao People's Democratic Republic (Laos). BMC Public Health. 2013;13:444.

30. Alkenbrack S, Jacobs B, Lindelow M. Achieving universal health coverage through voluntary insurance: what can we learn from the experience of Lao PDR? BMC Health Serv Res. 2013;13:521.

31. Alkenbrack S, Lindelow M. The impact of community-based health insurance on utilization and out-of-pocket expenditures in Lao People's Democratic Republic. Health Econ. 2015;24(4):379-99.

32. Alvesson HM, Lindelow M, Khanthaphat B, Laflamme L. Shaping healthcareseeking processes during fatal illness in resource-poor settings. A study in Lao PDR BMC Health Serv Res. 2012;12:477.

33. Paphassarang C, Philavong K, Boupha B, Blas E. Equity, privatization and cost recovery in urban health care: the case of Lao PDR. Health Policy Plan. 2002 17(Suppl):72-84

34. Syhakhang L, Soukaloun D, Tomson G, Petzold M, Rehnberg C, Wahlstrom $R$. Provider performance in treating poor patients--factors influencing prescribing practices in lao PDR: a cross-sectional study. BMC Health Serv Res. 2011;11:3.

35. Nguyen TN, Thu PN, Hung NT, Son DH, Tien NT, Van Dung N, Quang HH, Seidlein LV, Cheah PY, Dondorp AM, et al. Community perceptions of targeted anti-malarial mass drug administrations in two provinces in Vietnam: a quantitative survey. Malar J. 2017;16(1):17.

36. Peto TJ, Tripura R, Sanann N, Adhikari B, Callery J, Droogleever M, Heng C, Cheah PY, Davoeung C, Nguon C, et al. The feasibility and acceptability of mass drug administration for malaria in Cambodia: a mixed-methods study. Trans R Soc Trop Med Hyg. 2018;112(6):264-71.

37. Kajeechiwa L, Thwin MM, Shee PW, Yee NL, Elvina E, Peapah P, Kyawt K, Oo PT, PoWah W, Min JR, et al. The acceptability of mass administrations of anti-malarial drugs as part of targeted malaria elimination in villages along the Thai-Myanmar border. Malar J. 2016;15(1):494.

38. De Martin S, von Seidlein L, Deen JL, Pinder M, Walraven G, Greenwood B. Community perceptions of a mass administration of an antimalarial drug combination in the Gambia. Tropical Med Int Health. 2001;6(6):442-8.

39. Musoke D, Boynton P, Butler C, Musoke MB. Health seeking behaviour and challenges in utilising health facilities in Wakiso district, Uganda. Afr Health Sci. 2014;14(4):1046-55.

40. Kuuire VZ, Bisung E, Rishworth A, Dixon J, Luginaah I. Health-seeking behaviour during times of illness: a study among adults in a resource poor setting in Ghana. J Public Health (Oxf). 2015.

41. Adhikari B, Phommasone K, Kommarasy P, Soundala X, Souvanthong P, Pongrongsa T, Henriques G, Newton PN, White NJ, Day NPJ, et al. Why do 
people participate in mass anti-malarial administration? Findings from a qualitative study in Nong District, Savannakhet Province, Lao PDR (Laos). Malar J. 2018;17(1):15.

42. Alvesson HM, Lindelow M, Khanthaphat B, Laflamme L. Coping with uncertainty during healthcare-seeking in Lao PDR. BMC Int Health Hum Rights. 2013;13:28.

43. Verschuere J, Decroo T, Lim D, Kindermans JM, Nguon C, Huy R, Alkourdi Y, Peeters Grietens K, Gryseels C. Local constraints to access appropriate malaria treatment in the context of parasite resistance in Cambodia: a qualitative study. Malar J. 2017;16(1):81.

44. Liverani M, Nguon C, Sok R, Kim D, Nou P, Nguon S, Yeung S. Improving access to health care amongst vulnerable populations: a qualitative study of village malaria workers in Kampot, Cambodia. BMC Health Serv Res. 2017; 17(1):335

45. Herdman MT, Maude RJ, Chowdhury MS, Kingston HW, Jeeyapant A, Samad R, Karim R, Dondorp AM, Hossain MA. The relationship between poverty and healthcare seeking among patients hospitalized with acute febrile illnesses in Chittagong, Bangladesh. PLoS One. 2016;1 1(4):e0152965.

46. Acharya J, Kaehler N, Marahatta SB, Mishra SR, Subedi S, Adhikari B. Hidden costs of hospital based delivery from two tertiary hospitals in Western Nepal. PLoS One. 2016;11(6):e0157746.

47. Ukwaja KN, Alobu I, Nweke CO, Onyenwe EC. Healthcare-seeking behavior, treatment delays and its determinants among pulmonary tuberculosis patients in rural Nigeria: a cross-sectional study. BMC Health Serv Res. 2013;13:25.

48. Canavati SE, Lawpoolsri S, Quintero CE, Nguon C, Ly P, Pukrittayakamee S, Sintasath D, Singhasivanon P, Peeters Grietens K, Whittaker MA. Village malaria worker performance key to the elimination of artemisinin-resistant malaria: a Western Cambodia health system assessment. Malar J. 2016;15(1):282.

49. Ahmed SM, Adams AM, Chowdhury M, Bhuiya A. Gender, socioeconomic development and health-seeking behaviour in Bangladesh. Soc Sci Med. 2000;51(3):361-71.

50. Stevenson FA, Britten N, Barry CA, Bradley CP, Barber N. Self-treatment and its discussion in medical consultations: how is medical pluralism managed in practice? Soc Sci Med. 2003;57(3):513-27.

51. Sydara K, Gneunphonsavath S, Wahlstrom R, Freudenthal S, Houamboun K, Tomson G, Falkenberg T. Use of traditional medicine in Lao PDR. Complementary therapies in medicine. 2005:13(3):199-205.

52. Abubakar A, Van Baar A, Fischer R, Bomu G, Gona JK, Newton CR. Sociocultural determinants of health-seeking behaviour on the Kenyan coast: a qualitative study. PLoS One. 2013;8(11):e71998.

53. Atwine F, Hultsjo S, Albin B, Hjelm K. Health-care seeking behaviour and the use of traditional medicine among persons with type 2 diabetes in SouthWestern Uganda: a study of focus group interviews. Pan Afr Med J. 2015;20:76.

54. Tambiah SJ. Buddhism and the spirit cults in north-east Thailand. Cambridge, United Kingdom: Cambridge University Press; 1970.

Ready to submit your research? Choose BMC and benefit from:

- fast, convenient online submission

- thorough peer review by experienced researchers in your field

- rapid publication on acceptance

- support for research data, including large and complex data types

- gold Open Access which fosters wider collaboration and increased citations

- maximum visibility for your research: over $100 \mathrm{M}$ website views per year

At $\mathrm{BMC}$, research is always in progress.

Learn more biomedcentral.com/submissions 